\title{
LABORATORY EXPERIMENT ON BIOLOGICAL DECOMPOSITION OF BIOLOGICAL REACTOR LANDFILL
}

\author{
SUN, H. J.* - BIAN, X. Y. - ZHAO, L. H. - QIU, G. \\ School of Civil and Architectural Engineering, Liaoning University of Techonlogy \\ Jinzhou 121001, LiaoNing, China \\ *Corresponding author \\ e-mail: sunhongjun_2006@163.com \\ (Received 24 $4^{\text {th }}$ Aug 2018; accepted $12^{\text {th }}$ Nov 2018)
}

\begin{abstract}
In order to study the bio-decomposition of bioreactor landfill waste, simulation experiment of different ways of landfill and decomposition stage was conducted. We analyzed decomposition processes of organic matter in different decomposition stages. The landfill can be divided into two types in bioreactor: stratified landfill and non-stratified landfill, each group having four waste decomposition reaction stages. By collecting the reaction gas and leachate in each stage, methane production, $\mathrm{pH}$, moisture content and volatile solids were measured, and the pattern of bio-decomposition was obtained. The results showed that with the gradual deepening of organic matter decomposition in waste, the methane production rate and the $\mathrm{pH}$ value of leachate will change greatly. The weight percentage of the biodegradable material gradually decreased and the average moisture content of waste increased from $54.6 \%$ to $70.2 \%$. The content of volatile solids in waste decreased from $89 \%$ to $51 \%$.
\end{abstract}

Keywords: bioreactor landfill, biodegradation, leachate, experimental study, organic matter

\section{Introduction}

Bioreactor landfill speeds up the bio-decomposition of the organic matter through secondary leachate injection and improves the landfill stabilization process. The technology has been widely used in the field. The bioreactor landfill waste's decomposition of organic matter is greatly differs from that of the traditional landfill (Stark and Newman, 2010). Kjeldsen et al. (2002), Chugh (1998) and Ghanem et al. (2001) put forward the changing range of $\mathrm{pH}$ 4.7-8.8 in traditional landfill and the $\mathrm{pH}$ value was 5.4-8.6 floating in the bioreactor landfill. Olivier and Gourc (2007) and Binder and Bramryd (2001) also pointed out that the $\mathrm{pH}$ of waste body changed from 6.5 to 7.6 in the anaerobic decomposition stages. Beaven (2004) and Qian and Koerner (2004) explicitly proposed different moisture content of waste body in the traditional landfill and the bioreactor landfill. Landva et al. (2000) and Clark (2007), Barlaz et al. (2001), Shen (2002) pointed out the change of the organic matter content 5\%-75\% in the landfill. Kong et al. (2008) put forward creepdecomposition experiment to couple under leachate recharge, Xie et al. (2005) conducted contrast tests of waste compression characteristics and decomposition characteristics under constant load.

In order to research the characteristics of bioreactor landfill waste bio-decomposition a large number of laboratory tests of bioreactor landfill waste bio-decomposition still needs to be conducted. Considering representativeness of the waste sample in laboratory test, all waste samples were collected in Jinzhou Nan-shan Landfill of Liaoning province, China. The samples were fully mixed and test samples were selected when in need. The test samples were divided into two groups; the first group is the direct landfill waste sample, the second group is the layered rubbish sample, which is placed between the soil covering layers. This arrangement can simulate the actual landfill. The landfill was constituted of 
four phases, which were aerobic and anaerobic decomposition of waste, methane fermentation and reduced rate methane production. Reaction gases and leachate were collected in each stage. Methane production rate, $\mathrm{pH}$, changes of organic matter in different stages of decomposition, moisture content, volatile solid content and other related indicators were studied. It can be concluded that the biodegradable pattern of the bioreactor landfill waste and decomposition characteristics under different decomposition stages.

\section{Materials and methods}

\section{In situ sample collection}

Due to the complexity of the components of waste in landfills, the accuracy of geotechnical parameter measurement of waste body is affected by the rubbish sample. Therefore, the conducted garbage is a representative sample which will determine the scientific test result. The samples were collected in Jinzhou Nan-shan Landfill, China (Fig. 1). According to the standard methods of geotechnical test, a typical mixed waste sample was obtained. The collected waste sample was mixed several times, and then it was divided into four parts. One part was selected, the other three were discarded. Finally, the selected portion of the waste sample mixed thoroughly again and divided into four parts. One part from the heap was selected and the other three parts were discarded. The selected part of the waste was used in the test.

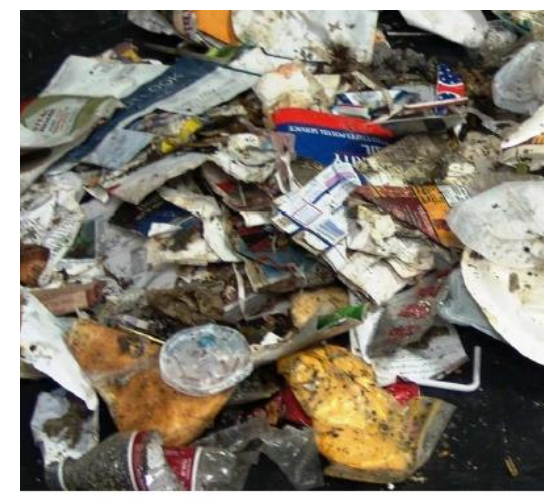

Figure 1. Waste samples

\section{Test method}

In order to study physical characteristics and strength parameters of the waste body under different decomposition stages, the project team developed two sets of laboratory experiments for this test, as it is shown in Figure 2. Each reactor corresponded to an experiment and each group included four reactors representing different decomposition stages of waste. The first set of test involved layered waste with no covering by soil layer. The second set of test involved layered waste with soil covering. First of all, the reactor and the gas collecting device and leachate device were connected; the reactor was sealed with o-rings and sealant. A u-shaped pressure gauge was connected by the gas collecting device. The $\mathrm{U}$ type pressure gauge providing water pressure difference was observed at $48 \mathrm{~h}$ in order to check the seal of the reactor. In the test, the water pressure difference was $2 \mathrm{~mm}$ in $12 \mathrm{~h}$ and the water pressure difference was $5 \mathrm{~mm}$ in 48 $\mathrm{h}$, which meet the sealing performance. 


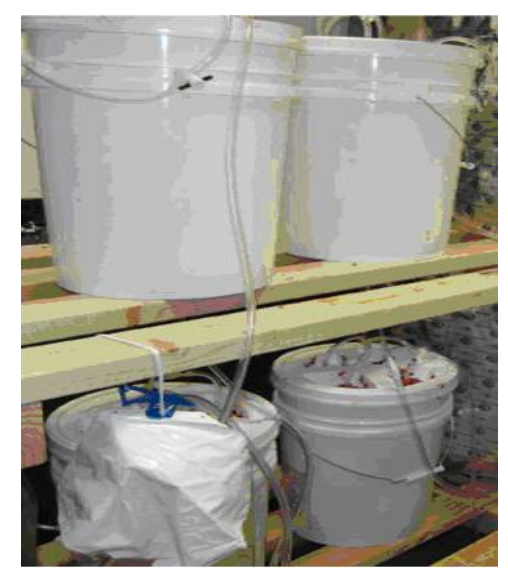

Figure 2. The diagram of simulation experiment

The weight of waste was measured before the waste was filled into the reactor (Fig. 3). To guarantee the uniformity of waste, waste was mixed adequately before placed into the bioreactor. Two groups of reactor were filled. The first reactor was directly filled and compacted. In the second reactor an actual processing form of a landfill was simulated. Each layer of landfill was covered by soil.

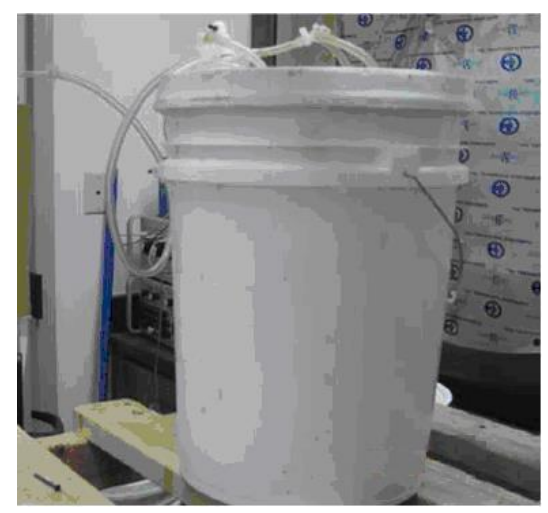

Figure 3. Leak test of reactor

Ensuring that $1500 \mathrm{ml}$ of leachate is produced every day the amount of recharge water poured into the reactor was determined based on the initial water content of the garbage sample, and on the initial moisture content of the test sample. Ensuring that the amount of water is poured into the reactor, the moisture content of the garbage sample reaches $55 \%$. Finally, the reactor was closed, the gas collection device and the leachate collection bag were connected, and the two sets of reactors were set under $28-32{ }^{\circ} \mathrm{C}$ (Qiu et al., 2010).

Each reactor was operated under the conditions of a simulated bioreactor to ensure the accuracy and the scientificity of the test by performing the following operation procedure (Qian and Koerner, 2010):

1. Injection of enough amount of water in the reactor to accelerate the production of leachate;

2. Recharging the leachate to the reactor; 
3. Using activated sludge process, adding anaerobic digestion into the leachate to speed up decomposition of organic matter of waste in the reactor.

\section{The formation samples in different decomposition stages}

The waste samples of different decomposition stages were generated under appropriate waste leachate re-circulation and organic matter decomposition conditions by two bio reactors. Each test included four reactors of different decomposition stages. The four decomposition stages were aerobic, anaerobic, methane fermentation and reduced rate methane production phase. Gas, $\mathrm{pH}$ value and volatile solids composition in this experiment were used to judge stages of the decomposition of organic matter.

\section{Results and discussion}

With the continuous progression of the organic matter degradation step in the garbage sample, the production rate of methane and the $\mathrm{pH}$ value of the leachate change greatly. Figures 4 and 5 showed the statistics of the methane production rate and $\mathrm{pH}$ values respectively. In this experiment, leachate was treated by an anaerobic digestion sludge method, and then fed back to the reactor to accelerate the degradation of the organic matter in the reactor. Two sets of tests were conducted on different stages of degradation of garbage samples according to changes in the degradation process. In the first set of tests, the garbage sampling time in the reactor were the 26th day, the 107th day, the 224th day and the 249th day; in the second set of tests, the garbage sampling time in the reactor were the 21 st day, the 96th day, the 172nd day and the 234th day. Figure $4 a$ shows the yield of methane at different stages of degradation in the first set of experiments, and Figure $4 b$ shows the change in $\mathrm{pH}$ of the leachate at different steps of degradation in the first set of tests. On the 26th day, the sample went through an anaerobic acidification step, which was phase I. On the 107th day, the methane production rate reached the peak and the $\mathrm{pH}$ value was basically neutral. The degradation of the organic matter in the garbage body at this step was very active. This is Phase II; the 224th day sample and the 249th day sample were in the methane production rate reduction stage, that is step III and the maturation step of garbage body degradation, that is step IV, respectively. Using the same method and principle, in the second set of reactors, the extraction time of the samples was 21 days, 96 days, 172 days, and 234 days, respectively. They corresponded to the first step of bio-degradation and the second set of samples, which are Phase II, Phase III and Phase IV. The results are presented in Figure 5. The methane production rates in reactors at different decomposition phases are presented in Table 1.

Table 1. Methane production in the two different reactors

\begin{tabular}{c|c|c|c|c}
\hline \multirow{2}{*}{$\begin{array}{c}\text { Decomposition } \\
\text { phase }\end{array}$} & \multicolumn{2}{|c|}{ Reactor 1 } & \multicolumn{2}{c}{ Reactor 2 } \\
\cline { 2 - 5 } & Time (day) & Methane production (L) & Time (day) & Methane production (L) \\
\hline Phase I & 26 & 23.38 & 21 & 13.67 \\
Phase II & 107 & 194.03 & 96 & 231.24 \\
Phase III & 224 & 473.87 & 172 & 342.12 \\
Phase IV & 249 & 514.15 & 234 & 557.62 \\
\hline
\end{tabular}




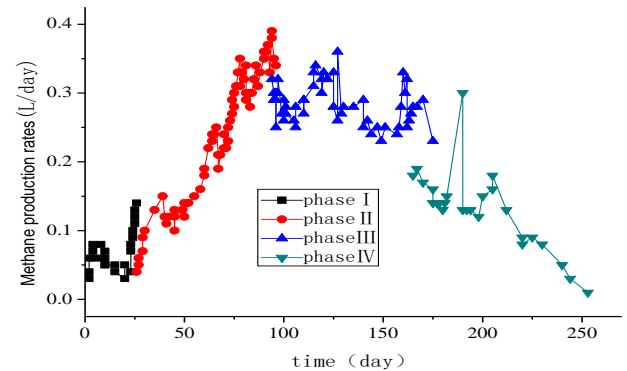

$\mathbf{a}$

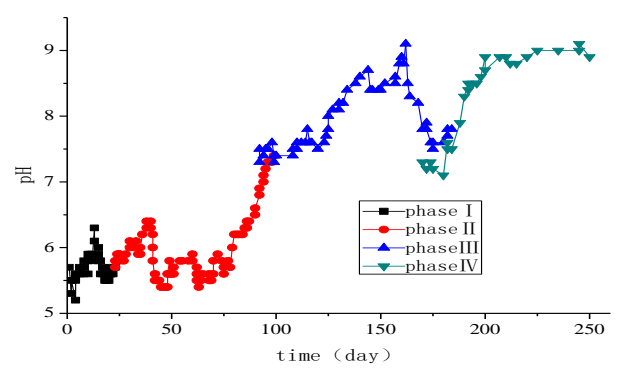

b

Figure 4. The methane production rate (a) and $\mathrm{pH}(\mathrm{b})$ of different decomposition stages of the first test

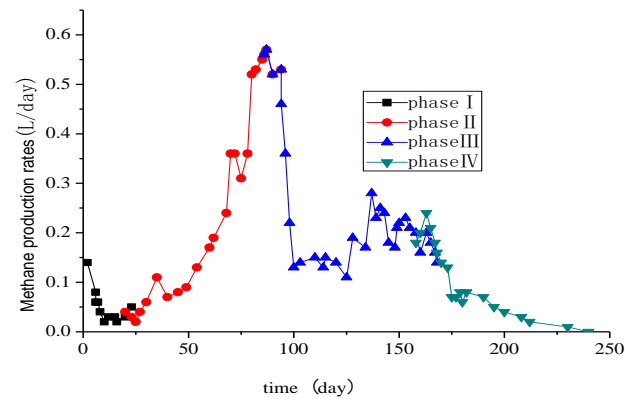

a

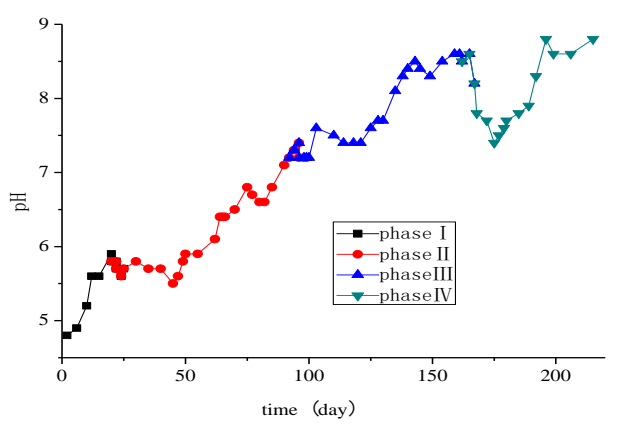

b

Figure 5. The methane production rate $(a)$ and $\mathrm{pH}(b)$ of different decomposition stages of the second test

\section{Change of waste composition in different decomposition stages}

The change in weight percentage of waste composition at each phase of decomposition is a big difference. The decomposition of waste reduced the degradable component in waste considerably, while the non degradable component (plastic) remained the same. The rate of decomposition also depended on the type of individual constituent. In Figure 6 it can be observed that the food wastes were completely consumed by the end of the second phase. On the other hand, only $28 \%$ of paper was degraded in this phase. However at the end of the final phase of decomposition the decomposition of paper increased. The paper present in the final phases of decomposition was more like a paste with higher moisture content. This is why a small reduction in the percentage of paper was observed in the final phases of decomposition only. Paper is a major biodegradable waste that has a strong impact on the geotechnical characteristics of waste. As the waste degraded, the percentage of paper decreased, while the percentage of plastic increased. Figure 6 presents the percentage of paper and plastic at the end of each phase of decomposition.

\section{The results of moisture content analysis}

With the progression of the degradation step, the average moisture content of the garbage was also increasing, and the moisture content of the landfill is shown in Table 2. In the first set of reactors, the moisture content increased from $58.6 \%$ in step I to $64.9 \%$ in step 
IV. In the second set of reactors, the moisture content increased from $54.6 \%$ in step I to $70.2 \%$ in step IV. The change of moisture content can help to distinguish the organic matter degradation step of the garbage body. The degradation of the garbage body reduces the void ratio of itself, but it also increases the moisture content.

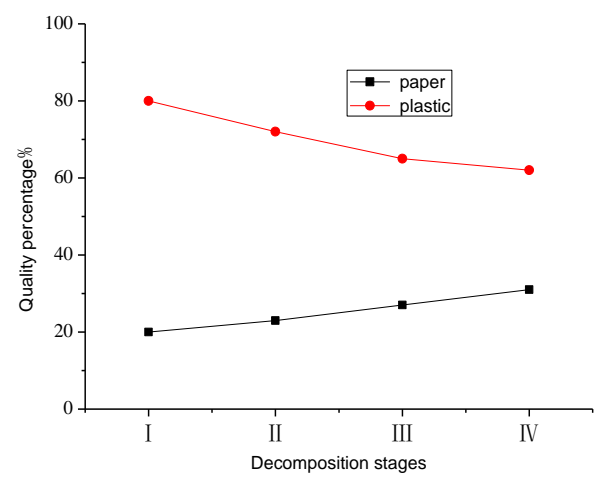

Figure 6. The percentage content of waste paper and plastic in different decomposition stages

Table 2. Moisture content of the solid waste in different degradation stages

\begin{tabular}{c|c|c}
\hline Decomposition phase & Reactor 1 & Reactor 2 \\
\hline Phase I & 58.6 & 54.6 \\
Phase II & 59.2 & 60.4 \\
Phase III & 64.1 & 68.5 \\
Phase IV & 64.9 & 70.2 \\
\hline
\end{tabular}

\section{The results of volatile solids analysis}

After each step of degradation was completed, the percentage of solids in the trash was determined and the results are shown in Figure 7. Leachate recharge has a great influence in the degradation of the garbage sample. With the degradation of the garbage sample, the volatile solid content in the garbage sample is gradually reduced. The percentage of volatile solids showed a big change after each degradation step. In the first set of reactors, the percentage of volatile solids dropped from $94 \%$ in Phase I to $41 \%$ in Phase IV; in the second set of reactors, the percentage of volatile solids was $89 \%$ in Phase I and $51 \%$ in Phase IV (Table 3).

Table 3. The percentage content of volatile solids in different degradation stages

\begin{tabular}{c|c|c|c|c}
\hline \multirow{2}{*}{$\begin{array}{c}\text { Decomposition } \\
\text { phase }\end{array}$} & \multicolumn{2}{|c|}{ Reactor 1 } & \multicolumn{2}{c}{ Reactor 2 } \\
\cline { 2 - 5 } & $\begin{array}{c}\text { Waste } \\
\text { decomposition } \\
\text { period (d) }\end{array}$ & $\begin{array}{c}\text { The percentage } \\
\text { content of volatile } \\
\text { solids (\%) }\end{array}$ & $\begin{array}{c}\text { Waste } \\
\text { decomposition } \\
\text { period (d) }\end{array}$ & $\begin{array}{c}\text { The percentage } \\
\text { content of volatile } \\
\text { solids (\%) }\end{array}$ \\
\hline Phase I & 26 & 6 & 21 & 11 \\
Phase II & 107 & 26 & 96 & 22 \\
Phase III & 224 & 38 & 172 & 41 \\
Phase IV & 249 & 59 & 234 & 49 \\
\hline
\end{tabular}




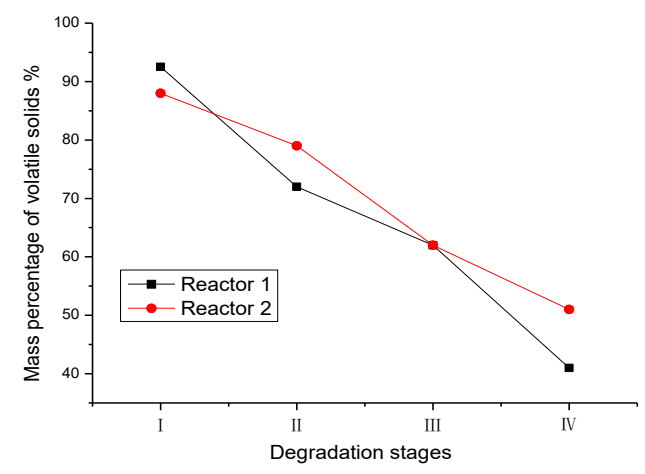

Figure 7. The mass percentage of volatile solids in different degradation stages

\section{Conclusion}

A laboratory test instrument of organic matter decomposition of bioreactor landfill has been developed. This instrument has gas and leachate collection device. The test has shown that the equipment's performance is stable. The test was divided into two groups. The first test in the landfill was not layered, without covering soil layer. The second test was layered, and each layer of waste was covered by soil, each test was consisted of four stages of decomposition. With the progression of decomposition stage of waste body's organic matter, the rate of $\mathrm{CH}_{4}$ and $\mathrm{pH}$ of leachate have greatly changed, methane production reached its peak period, and the $\mathrm{pH}$ was neutral. The percentage of biodegradable material weight was gradually decreased, but non-biodegradable material remained the same in the process with the progression of the decomposition stage. With the progression of the decomposition stage, the average moisture content of waste body increased, the moisture content raised from 58.6\% in Phase I to 64.9\% in Phase IV. Similarly in Reactor 2, it increased from 54.6\% in Phase I to 70.2\% in Phase IV. As the garbage body degrades, the content of volatile solids in the garbage body gradually decreases. The percentage of volatile solids in the first set of reactors decreased from $94 \%$ in phase I to $41 \%$ in phase IV. As for the second set, the percentage of volatile solids in the reactor dropped from $89 \%$ in phase I to $51 \%$ in Phase IV.

Acknowledgements. This work was supported and financed by the grant No. 51408290 from National Natural Science Foundation of China.

\section{REFERENCES}

[1] Barlaz, E., Beech, J. F., Matasovic, N. (2001): Discussion of Municipal solid waste slope failure: Waste and foundation soil properties. - J Geotech Geoenviron Eng 127(9): 812813.

[2] Beaven, X. (2004): Limit equilibrium analysis of translational failure of landfills under different leachate buildup conditions. - Water Sci Eng 1(1): 44-62.

[3] Binder, M., Bramryd, T. (2001): Environmental impacts of landfill bioreactor cells in comparison to former landfill techniques. - Water, Air and Soil Pollution 129(1-4): 289303.

[4] Chugh, S. (1998): Effect of recirculated leachate volume on MSW degradation. - Waste Manage and Research 16(6): 64-573. 
[5] Clark, J., Augenstein, D., Morck, R. (2007): Bioreactive landfill. - MSW Management 10: 53-60.

[6] Ghanem, I. I., Guowei, G., Jinfu, Z. (2001): Leachate production and disposal of kitchen food solid waste by dry fermentation for biogas generation. - Renewable Energy 23(3-4): 673-684.

[7] Kjeldsen, P., Barlaz, M., Rooker, A. (2002): Present and long-term composition of msw landfill leachate. A review. - Critical Reviews in Environmental Science and Technology 32(4): 297-336.

[8] Kong, X., Sun, X.-L., Zou, D. (2008): Creep-degradation Properties of municipal solid waste in laboratory test. - Rock and Soil Mechanics 2(29): 337-341.

[9] Landva, A. O., Valsangkar, A. J., Pelkey, S. G. (2000): Lateral earth pressure at rest and compressibility of municipal solid waste. - Canadian Geotechnical Journal 37(6): 11571165 .

[10] Olivier, F., Gourc, J. P. (2007): Hydro-mechanical behavior of municipal solid waste subject to leachate recirculation in a large-scale compression reactor cell. - Waste Management 27: 44-58.

[11] Qian, X., Koerner, R. M. (2004): Effect of apparent cohesion on translational failure analyses of landfills. - J Geotech Geoenviron Eng 130(1): 71-80.

[12] Qian, X., Koerner, R. M. (2010): Modification to translational failure analysis of landfills incorporating seismicity. - J Geotech Geoenviron Eng 136(5): 718-727.

[13] Qiu, G., Liang, L., Sun, H. (2010): Forecasting the settlement of a bioreactor landfill based on gas pressure changes. - Waste Management \& Research 31(8): 1035-1040.

[14] Shen, D. S., He, R., Ren, G. P., Traore, I., Feng, X. S. (2002): Effect of leachate recycle and inoculation on microbial characteristics of municipal refuse in landfill bioreactors. Journal of Environmental Science 14(3): 406-412.

[15] Stark, T. D., Newman, E. J. (2010): Design of a landfill final cover system. - Geosynthet Int 17(3): 124-131.

[16] Xie, Y., Chen, Y., Tang, X. (2005): Development and application of biodegradationcompression test apparatus for municipal solid waste. - Chinese Journal of Geotechnical Engineering 5(27): 571-576. 